\section{The combinations of the sexes of familial cases of neural tube defect}

Mariman and $\mathrm{Hamel}^{1}$ report that in families where two offspring are affected with neural tube defects (NTD) there are more same sex affected pairs than opposite sex affected pairs. A number of points arise.

(1) The null hypothesis (as expressed by binomial expectation) is not that there should be exact equality because the sex ratio (proportion male) of cases is not exactly 0.5 .

(2) Since the sex ratios of spina bifidas in general exceed those of anencephalics, ${ }^{23}$ one would expect concordance for sex in affected NTD sib pairs if the defects, to some extent 'breed true'. There is evidence for such a suggestion, ${ }^{4-6}$ though the point has been disputed.' Account has been taken of such a possibility by disaggregating the data into sib pairs of anencephalics, sib pairs of spina bifidas, and pairs comprising one of each ${ }^{7}$ In that paper, data were pooled from a number of sources, and the table here reproduces those pooled data. None of these three individual distributions, nor (more important) their components treated separately, nor their overall total, shows a significant departure from binomial expectation.

The combinations of the sexes of cases of neural tube defect in sibships in which exactly two are affected (by the nature of the defects) (reproduced from fames').

\begin{tabular}{lrrr}
\hline Defects & MM & MF & FF \\
\hline 2 anencephalics & 9 & 35 & 48 \\
2 spina bifidas & 38 & 73 & 57 \\
1 anencephalic + & 15 & 75 & 62 \\
1 spina bifida & 62 & 183 & 167 \\
\hline
\end{tabular}

(3) It is well established that in samples in which anencephaly is relatively common, the sex ratio of cases is lower than in samples in which it is rare. ${ }^{2}$ This suggests two causes, one (presumably environmental) being responsible for mainly female cases, and the other (possibly genetic) for cases of both sexes. Such a notion is strengthened by the observations $^{8}$ that (i) vitamin therapy resulted in a greater reduction of incidence in Northern Ireland (previously a high risk area) than in south-east England (previously a low risk area), and (ii) there was an excess of males among the recurrences which occurred to the supplemented mothers.

However, since the sex ratio of cases born to anencephalic prone women does not differ appreciably from that of those born to other women, ${ }^{9}$ it was inferred that the typical case is the result of both causes acting simultaneously on the same woman, rather than separately on different women. It remains to be seen whether this form of reasoning will prove useful in the search for causes.

Mariman and $\mathrm{Hamel}^{1}$ speculate that (i) there is concordance within multiple case sibships for location of lesion, and (ii) there is an association between location of lesion and sex of case. If both these premises were true, there should be concordance for sex within sibships. So the present data suggest that at least one of these premises is false.

WILLIAM H JAMES

Department of Genetics and Biometry, University College London, Wolfson House, 4 Stephenson Way,
1 Mariman ECM, Hamel BCJ. Sex ratios of affected and transmitting members of multiple case ted and transmitting members of multiple case 1992;29:695-8.

2 James WH. The sex ratio in anencephaly. $\mathcal{F ~ M e d}$ Genet 1979;16:129-33.

3 James WH. The sex ratio in spina bifida. $\mathcal{F}$ Med Genet 1979;16:384-8.

4 Smithells RW, D'Arcy EE, McAllister EF. The outcome of pregnancies before and after the birth of infants with nervous system malformations. Dev Med Child Neurol 1968;suppl 15:6-10.

5 Richards IDG, McIntosh HT, Sweenie S. A genetic study of anencephaly and spina bifida in Glasgow Dev Med Child Neurol 1972;14:626-39.

6 Carter CO. Clues to the aetiology of neural tube malformations. Dev Med Child Neurol 1974;suppl 32:3-15.

7 James WH. Sexes of affected cases in sibships containing two or more members with anencontaining two or more members with anencephaly or spin

8 Seller MJ, Nevin NC. Periconceptional vitamin supplementation and the prevention of neura tube defects in south-east England and Northern Ireland. 7 Med Genet 1984;21:325-30.

9 James WH. The sex ratios of anencephalics born to anencephalic-prone women. Dev Med Child Neurol 1980;22:618-22.

\section{BOOK REVIEWS}

All titles reviewed here are available from the BMJ Bookshop, PO Box 295, London WC1H 9TE. Prices include postage in the UK and for members of the British Forces Overseas, but overseas customers should add $15 \%$ to the value of the order for postage and packing. Payment can be made by cheque in sterling drawn on a UK bank, or by credit card (Mastercard, Visa, or American Express) stating card number, expiry date, and full name.

Fetal Tissue Transplants in Medicine. Ed Robert G Edwards. (Pp 352; £60.00.) London: Cambridge University Press. 1992.

I came to this book as a clinical neurologist interested in the potential for fetal grafting in treating brain diseases. Geneticists, embryologists, and ethicists quite probably have different agendas. Among those tempted by the title, there is something for everyone but, perhaps with the exception of the distinguished editor, few will find all the chapters either relevant or wholly comprehensible. The book therefore strikes me as a bit of a reverend's oocyte, to be dipped into in the library but not necessarily bought and read in its entirety. Nevertheless, it is a valuable source of useful material in an embryonic, but rapidly expanding, field.

Of the 13 chapters, the ones I personally found useful were those on 'Organogenesis and CNS development', 'The procurement of human fetal tissues for clinical transplantation', 'The biology of fetal brain tissue grafts', 'Cell grafting and gene therapy in metabolic diseases', and 'Law and ethics of transplanting fetal tissue'. In the last of these, most of the Reverend Polkinghorne's recommendations sound pretty sensible to me, but not all. For example, will the impermissibility of a tissue bank expressing a preference or need for material from a specific trimester eventually seem as dubious as Thomas Aquinas's pronouncement that ensoulment takes place at 40 days in a male, and at 90 days in a female fetus?

Areas outside my specific field of competence or interest were grafts of haemopoietic and immunogenic tissue, gonads, and corneas. However, the chapter on clinical results of transplanting human fetal pancreas was depressingly familiar and familiarly depressing. Thus, from over 100 human fetal nigral cell grafts in parkinsonians, there is conclusive evidence of success in only four; some others may well have been successful, but definite proof is lacking. Similarly, despite 1582 human fetal pancreatic grafts for diabetes up to June 1990 and "numerous claims of graft functions", in only four patients has graft survival been shown, and in none of these is there conclusive evidence of graft functioning. Excellent basic and preclinical work in this field so often seems to fall at the last hurdle with clinicians who can operate with great skill but inadequately understand the disease they are experimenting upon, and hence lack the means to show whether the procedure itself has been effective. I have heard one such pioneer claim that because of information overload from his vast and inconclusive series, fewer data should be collected from each subject. On the contrary, rather like Aesop's tortoise, I tend to feel that the opposite approach (meticulous controlled monitoring of a few carefully studied subjects) has more to offer. If this message is beginning to trickle through, then perhaps the recent temporary moratorium on NIH funding for human fetal grafts in the USA may actually have been no bad thing.

\section{NIALL QUINN}

Molecular Basis of Inherited Disease. 2nd edition. K E Davies, A P Read. (Pp 95; £8.95.) Oxford: IRL Press. 1992.

Human molecular genetics is one of the most rapidly developing fields within the biological sciences and this coupled with its widespread importance for clinical practice means that many scientists and clinicians need an introduction to this subject. The first edition of Molecular Basis of Inherited Disease was very successful in this role and the second edition is an admirable successor. A second edition was essential to include new developments over the past four years, for example, interphase FISH, mutational screening approaches, unstable length mutations, genomic imprinting, and gene therapy.

Four sections cover the types of genetic markers, methods for locating genes (for single gene disorders), gene cloning strategies, and the molecular pathology of a variety of the commoner single gene disorders. A basic knowledge of DNA and the basic principles of genetics is assumed (as would be covered in school biology) but otherwise techniques and concepts are clearly explained with concise text and bicolour diagrams. References to original work and for further reading are included, as are two glossaries for technical and medical terms.

The present emphasis is rightly on the mapping and cloning of genes for the single gene disorders and I suspect that future editions will want to place more emphasis on approaches to the analysis of multifactorial disorders, to gene therapy, and to transgenic studies for elucidation of pathophysiology. Minor criticisms are the use of unusual sym- 
bols for autosomal recessive heterozygotes and the placing of the male line on the right in some pedigrees. I also wondered if the expense of a few colour plates of actual FISH (mapping and painting) might be considered in view of its major importance for research and clinical diagnosis in place of the simulated example.

\section{J M CONNOR}

Psychosocial Aspects of Genetic Counselling. Eds G Evers-Kiebooms, J P Fryns, J J Cassiman, H Van den Berghe. (Pp 203.) New York: Wiley-Liss. Birth Defects: Original Article Series, Volume 28(1), 1992.

This book contains the written papers based on spoken presentations given at the Second European Meeting on Psychosocial Aspects of Genetic Counselling held in Leuven, Belgium in September 1990. The first such conference was organised by Dutch genetic co-workers in 1988, with the dual aims of presenting papers on psychosocial research and comparing practice with colleagues throughout Europe. The steady increase in interest and activity in this area amongs genetic co-workers (counsellors, nurses, social workers), psychologists, and clinicians (geneticists, psychiatrists, and others) was reflected in the large number of participants at the third of these meetings which was held in Nottingham last September.

Despite its title, this book is not a comprehensive review of psychosocial issues in genetics, but is a collection of submitted papers (barring the invited paper by Seymour Kessler) reflecting the particular interests of their authors. The largest group of papers focus on reproductive decision making and the consequences of such decisions. Margaretha White-Van Mourik's comprehensive study of psychosocial sequelae following termination for abnormality, based on interviews with 84 couples two years' post-termination, is an important addition to the small body of publications on this topic. There are papers from groups in four different countries offering predictive tests for Huntington's disease; the paper by Guido de Wert from Maastricht on the ethical dilemmas posed in such testing is a challenging one, and points out that the right not to know is a new concept in medical ethics and solutions are far from clear. Two papers explore the extent to which genetic information is disseminated through families, and both suggest that apparent lack of interest in testing and counselling among, for example, female relatives of haemophilia patients or aunts and uncles of children with cystic fibrosis, may reflect ignorance rather than informed choice. Kessler points out that the bulk of genetic counselling psychosocial publications has focused on outcome, that is, reproductive decision making and risk recall perception, but that research into the process is scanty. He makes the important point that there is little direct evidence of what goes on in genetic counselling sessions. Perhaps al those unmade videotapes of real genetic counselling sessions contain the true resolution of the current debate as to whether genetic counselling is non-directive!
The papers in this volume do vary in quality but there is enough meat to provide several meals of thought for anyone involved in the practice or investigation of genetic counselling.

\section{KERZIN-STORRAR}

Molecular Genetics of Coronary Artery Disease: Candidate Genes and Processes in Atherosclerosis. Eds A J Lusis, J I Rotter, R S Sparkes. (Pp 453; £139.20.) London: Karger. 1992.

This book sets out to provide "a comprehensive description of our present state of knowledge of the cellular, molecular, and physiologic processes underlying atherosclerosis". It is a multiauthor book with 19 chapters divided into four sections describing the cellular events of atherosclerosis, lipoprotein metabolism, other risk factors, and a final section entitled, rather strangely, 'genetics'. The main difficulty for the editors of a book like this is to decide which audience they are aiming to attract, what level of previous knowledge to assume, and, particularly for complex multifactorial disorder such as coronary artery disease, how to present the various levels of complexity found in the disorder. Regarding this book, it is not clear whether it is aimed at the cardiologist/clinician who is interested in applying molecular genetic techniques, or at the molecular biologist who is thinking of tackling a new disorder. The other main problem of this book is that most of the chapters appear to have been written during 1990, and therefore are already almost two years out of date. In such a fast moving field, this is a serious problem, and certainly detracts from its value for anyone already involved in the field.

The different chapters do cover many of the basic aspects of what is known abou coronary artery disease, with a total of more than 2000 references in the book as a whole. However, many chapters do not shed light on the molecular genetics of the disorder, nor is there a serious attempt to pull together the different aspects of the genetic, biochemical, cellular, and physical processes that interact to cause the disease. The reader is therefore presented with a number of different snapshots of the problem, and left to his own devices to try to integrate them into the complete picture. In this the reader is not helped by the subject index which is poorly cross referenced between chapters.

Since the principal authors of the book are from Los Angeles, it is not completely surprising that the vast majority of the chapters are written by authors from the west coast of the USA or Canada, with only one European contributor and one from Australia. This undoubtedly gives a bias to the views presented, and in particular to the selection of references, and to the relative importance of the aspects covered. The chapter describing the cellular events is good and presents a useful overview with a number of helpful illustrations. The cellular interactions in atherosclerosis are very complex, and are not presented in a way that is easy to understand. The section on modified lipoproteins is com- prehensive, but does not reference a number of European contributions to the field, while the sections on viral genes and mechanical factors are well presented and very clear. In contrast, the sections on lipoprotein metabolism are both sketchy and repetitious; the part on high density lipoproteins would have benefited from the inclusion of figures or tables and hypertriglyceridaemia is poorly covered. The chapter on $\mathrm{Lp}(\mathrm{a})$ is clear, but gives no new insight into the mechanism of action of this intriguing lipoprotein, and I feel that for most of these sections these and other authors have presented more useful overviews in the last year or so. In contrast the section on bile acid synthesis and enterohepatic circulation is excellent and clearly written. In the section on risk factors there are chapters on hypertension, and the possible role of immunological processes, which focus rather heavily on American contributions to the field. The chapter on diabetes and risk factors is one of the clearer and most comprehensive, but it presents almost none of the very extensive body of publications on the relationship between coronary artery disease and diabetes in persons from the Indian subcontinent, and the relationship with central adiposity and insulin resistance. Similarly, the chapter on haemostatic factors is sketchy and much of the European based research in the field of coagulation and fibrinolysis has been underplayed. This is unfortunate since it is now well recognised that these factors are playing a major part in the development of coronary artery disease. The chapters on homocysteinuria and on genediet interaction and lipoprotein metabolism are very good and well worth reading, but a chapter on the molecular geography of inherited lipid disorders appears out of place. The section on the use of various types of genetic markers for the study of atherosclerosis falls between being too general and too specific to be of great use, and could probably have more helpfully appeared in the early part of the book. It contains a large appendix of all possible candidate genes for atherosclerosis and their RFLPs, but once again this is now out of date and the computer literate reader can easily obtain a more comprehensive list through a database search. The chapter on animal models is disappointing, with no mention at all of the use of transgenic animals or knock out experiments. This is a particularly serious oversight, since a great deal of fascinating information using these techniques has been obtained and published in the last two or three years.

Overall, I am not convinced that this book will be a worthwhile investment either for an individual person or for a department of clinical genetics or cardiology or medicine. Although some of the chapters are good overviews of the area, much of the information has been published in the last year or so in review form in scientific journals that are available in most university or medical school libraries. Although its comprehensive nature makes it attractive, the data presented and many of the conclusions have been rapidly overtaken by publications in the last two years, which make it, in my opinion, a rather poor investment for the price.

$S$ HUMPHRIES 